\title{
EVOLUÇÃO SUPÉRGENA DO CARBONATITO DE JUQUIÁ (SP)
}

\author{
Arnaldo ALCOVER NETO \\ Maria Cristina Motta de TOLEDO
}

\begin{abstract}
RESUMO
O intemperismo sobre as rochas carbonatíticas do complexo de Juquiá (SP) gerou uma jazida residual de fosfato apatítico com teores médios de $16 \%$ em $\mathrm{P}_{2} \mathrm{O}_{5}$. A rocha original é um carbonatito do tipo beforsito, que ocorre de maneira contínua, expondo, no atual nível de erosão, uma área de cerca de $2 \mathrm{~km}^{2}$ de material carbonatítico, o que não é comum nos maciços alcalinos com carbonatitos, onde estas rochas costumam ocorrer apenas como diques e veios.

A rocha primária é formada basicamente por dolomita rica em ferro e manganês e apatita (fluoridroxiapatita). Magnetita, barita e flogopita são acessórios, podendo chegar a 5\% do volume da rocha. Barita hidrotermal é facilmente encontrada em veios de até $1 \mathrm{~m}$ de espessura. A apatita primária pode chegar a $50 \%$ do volume da rocha original, sendo este o fator responsável pela manutenção das estruturas primárias em grande parte do manto de alteração e ainda pelos altos teores do minério residual.

As fácies de alteração provenientes do carbonatito representam um evento de dissolução dos carbonatos, seguido por reciclagem da apatita primária, com produção de apatita secundária. As composições mineralógica e química dos materiais estudados integradas às suas relações morfológicas permitiram considerações sobre o comportamento dinâmico das principais espécies químicas envolvidas, ressaltando:

- lixiviação intensa de $\mathrm{CO}_{3}^{2-}, \mathrm{Mg}^{2+}, \mathrm{H}_{4} \mathrm{SiO}_{4}, \mathrm{SO}_{4}^{2-}$ e $\mathrm{K}^{+}$,

- reciclagem no perfil de $\mathrm{PO}_{4}{ }^{3-}, \mathrm{Ca}^{2+}, \mathrm{Ba}^{2+}$ e subordinadamente $\mathrm{CO}_{3}{ }^{2-}$ e

- fixação preferencial e lixiviação eventual de $\mathrm{Fe}^{3+}, \mathrm{Ti}^{4+}, \mathrm{Al}^{3+}$ e $\mathrm{Mn}^{4+}$.
\end{abstract}

\begin{abstract}
Weathering of rocks of the alkaline carbonatitic complex of Juquiá (State of São Paulo, Brasil) resulted in a phosphatic residual ore with average $16 \% \mathrm{P}_{2} \mathrm{O}_{5}$. The primary rock contains iron and manganese - rich dolomite and apatite (fluorhydroxiapatite). Magnetite, baryte and phlogopite appear as accessories. Up to $50 \%$ of the carbonatite may be occupied by apatite, which is the main reason for the preservation of primary structures in the weathering mantle and for the high content in $\mathrm{P}_{2} \mathrm{O}_{5}$.

The weathering facies are consequent to dissolution of carbonates followed by recycling of primary apatite, with formation of secondary apatite. The mineralogical and chemical compositions of the material, and their morphological relations indicate the following dinamic behavior for the main chemical elements:

- strong depletion of $\mathrm{CO}_{3}^{2-}, \mathrm{Mg}^{2+}, \mathrm{H}_{4} \mathrm{SiO}_{4}, \mathrm{SO}_{4}{ }^{2-}$ and $\mathrm{K}^{+}$;

- recycling on the profile of $\mathrm{PO}_{4}{ }^{3-}, \mathrm{Ca}^{2+}, \mathrm{Ba}^{2+}$ and, subordinately, $\mathrm{CO}_{3}{ }^{2-}$;

- retention of $\mathrm{Fe}^{3+}, \mathrm{Ti}^{4+}, \mathrm{Al}^{3+}$ and $\mathrm{Mn}^{4+}$.
\end{abstract}

\section{INTRODUÇÃO}

1.1 O complexo alcalino-carbonatítico de Juquiá

O complexo alcalino de Juquiá localiza-se no sudeste do Estado de São Paulo (47²1' oeste e $24^{\circ} 24^{\prime}$ sul), no município de Registro. Dista aproximadamente $170 \mathrm{~km}$ da cidade de São Paulo, com acesso pela BR-116.

Constitui uma intrusão circular zonada, de cerca de $14 \mathrm{~km}^{2}$ de área atualmente exposta, encaixada em gnaisses parcialmente fenitizados. Dados geocronológicos anteriores, retrabalhados por SONOKI \& GARDA (1988), indicam idade de 133Ma para o maciço. Mais da metade da área total é ocupada por olivina-piroxenitos e piroxenitos, seguindo-se nefelina-sienitos, ijolitos, melteijitos e urtitos, além do carbonatito central ocupando cerca de $2,5 \mathrm{~km}^{2}$, formando um padrão subanelar concêntrico. Associados aos piroxenitos e nefelina-sienitos são também encontrados olivina-álcali gabros e essexitos/sienodioritos. Ocorrem ainda diques ankaratríticos e fonolitos (figura 1) (BORN, 1971; ULBRICH \& GOMES, 1981 e MACIOTTA et al., 1988). 

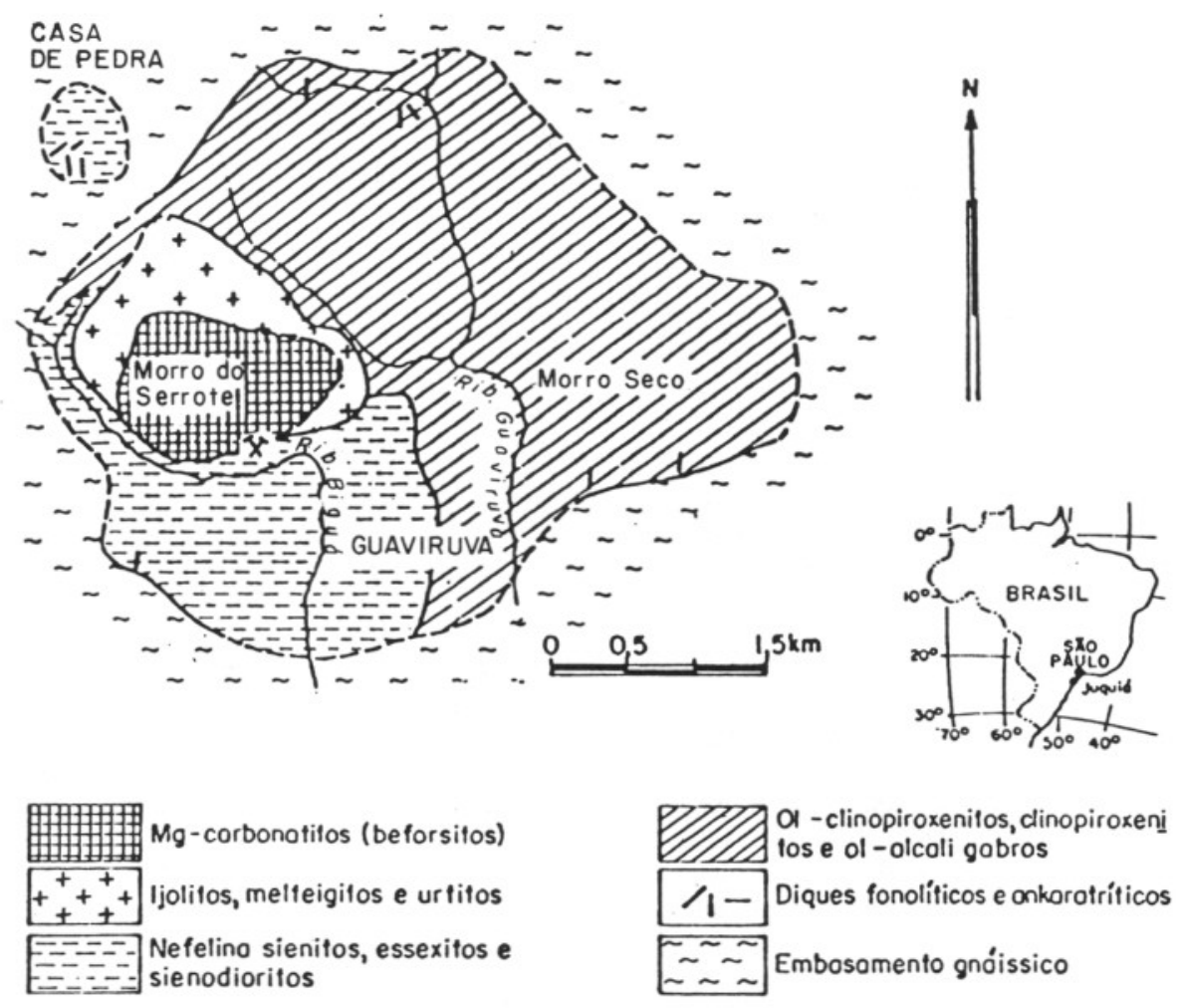

FIGURA 1 - Localização e mapa geológico do Complexo alcalino-carbonatitico de Juquiá, SP (adaptado de BORN, 1971 e MACCIOTTA et al., 1988).

Os carbonatitos de Juquiá foram classificados por BORN (op. cit.) em um tipo interno, bandado, de composição ankerítica e dolomítica, pobre em apatita, e outro tipo externo, de apatita-beforsito. Em ambos os casos, a apatita seria posterior aos carbonatos.

A existência de um corpo contínuo de carbonatito - ao contrário de vários outros complexos alcalinos, onde esta rocha ocorre em diques e veios restritos - e a associação da apatita à rocha carbonatítica e não às rochas silicáticas da intrusão promoveram uma situação particularmente favorável ao desenvolvimento de um perfil de alteração extremamente rico em $\mathrm{P}_{2} \mathrm{O}_{5}$, com média de $16 \%$, segundo RODRIGUES \& LIMA (1984), constituindo a concentração residual de apatita de maior teor em $\mathrm{P}_{2} \mathrm{O}_{5}$ no Brasil. Por outro lado, é também uma situação muito favorável ao estudo da alteração dos carbonatitos, já que praticamente não há influência das outras rochas em sua evolução, com exceção das zonas de contato.

A área do complexo alcalino faz parte da extensa baixada drenada pelo rio Ribeira de Iguape; os riachos afluentes têm altitudes em torno de $10 \mathrm{~m}$ e originam-se em brejos que ocupam grande parte das áreas baixas. As elevações apresentam altitudes entre 60 e $70 \mathrm{~m}$. Destaca-se neste relevo o Morro do Serrote, com 211m de altitude, formado pela porção carbonatítica da intrusão, com seu arcabouço preservado em grande parte num manto de alteração isalterítica.

O clima atual é quente e úmido, com pluviosidade anual média de $1.400 \mathrm{~mm}$, mais concentrados no verão, mas sem uma estação totalmente seca, e com temperatura média anual de $22^{\circ} \mathrm{C}$.

1.2 O estudo da alteração de complexos alcalinocarbonatíticos e o ciclo do fósforo

A maior parte dos recursos minerais associados aos complexos deste tipo é encontrada no manto de alteração, sobretudo nos casos de alteração intensa. No caso de rochas ricas em apatita, a lateritização promove enriquecimento relativo em fósforo, que não é praticamente lixiviado do perfil, enquanto ocorre a desestabilização dos outros minerais primários, carbonatos e silicatos. A fixação do fósforo não é necessariamente devida à estabilidade da apatita, já que esta acaba por se alterar também. Os estudos sobre fosfatos lateríticos efetuados principalmente sobre materiais sedimentares indicam que a evolução completa conduz a recristalizações dos fosfatos, normalmente na seguinte ordem, causando uma zonalidade vertical nos perfis de alteração: 
fosf. Cal (1) $\rightarrow$ fosf. CaII (2) $\rightarrow$ fosf. CaAlFe (3) $\rightarrow$ fosf. AlFe (4) $\rightarrow$ fosf. Al (5) + fosf. Fe (6)

(1): apatita primária

(2): apatita secundária

(3): palita, crandalita, wardita

(4): leucofilita, barrandita

(5): variscita, wavelita, augelita, senegalita

(6): estrengita

Nesta evolução, o cálcio, elemento normalmente solúvel, tem sua lixiviação retardada através da fixação nos fosfatos secundários. As principais tendências evolutivas são:

- descarbonatação da apatita primária;

- decréscimo em álcalis e hidratação;

- acréscimo da razão $\mathrm{Al}+\mathrm{Fe} / \mathrm{P}$;

- aumento do grau de oxidação do ferro (ZANIN, 1968; VIEILLARD et al., 1979; LUCAS et. al., 1980; FLICOTEAUX et. al., 1984).

Os fosfatos secundários, em particular a crandalita, são estruturas favoráveis à fixação de diversos elementos, como $\mathrm{Sr}, \mathrm{Ba}, \mathrm{ETR}$, U, Th e outros elementos comumente encontrados nas rochas dos complexos alcalino-carbonatíticos. Além disto, a presença de íons $\mathrm{PO}_{4}{ }^{3-}$ no perfil inibe a cristalização de gibbsita, já que o alumínio tende a participar da estrutura dos fosfatos secundários. Fosfatos de ferro são menos freqüentes na natureza que fosfatos de alumínio: as reações dos íons fosfato com hidróxidos de ferro são muito mais lentas e ocorrem somente em ausência de material argiloso ou em condições muito redutoras; assim, o ferro permanece predominantemente como oxi-hidróxidos, ao contrário do alumínio, que só forma gibbsita quando está em excesso em relação ao fósforo.

Segundo The British Sulfur Corporation Limited (1980), o comportamento do fósforo em depósitos sedimentares associados a calcários e margas, que pode ser adaptado para o fósforo associado a carbonatitos, seria o seguinte: num estágio inicial de alteração, soluções levemente ácidas permitiriam a dissolução dos carbonatos, originando um meio ligeiramente alcalino. A apatita, pouco solúvel neste meio, seria mantida estável. Nos níveis onde os carbonatos já foram totalmente solubilizados, um meio mais ácido favoreceria a dissolução da apatita. O fósforo assim solubilizado seria em parte fixado com outros cátions em fases secundárias (fosfatos de alumínio com $\mathrm{Ba}, \mathrm{Fe}, \mathrm{Sr}$, ETR e outros), e, em parte, migraria para níveis inferiores do perfil, eventualmente formando apatita secundária ao atingir horizontes levemente alcalinos. Dessa forma, explicar-se-ia o ciclo do fósforo no perfil, elemento até certo ponto residual, mas com sucessivas reciclagens determinadas pelas condições físico-químicas dos meios.

\section{OBJETIVOS E METODOLOGIA}

Este trabalho procurou caracterizar as fases primárias e secundárias existentes nos materiais em diversos estágios de alteração sobre os carbonatitos de Juquiá, tentando estabelecer as relações cronológicas e genéticas entre estas fases, com o objetivo de reconstituir a história evolutiva do material no ambiente superficial, em termos de filiações mineralógicas, modificações estruturais e, sempre que possível, o itinerário geoquímico dos elementos. Os dados foram principalmente qualitativos, não havendo objetivo de quantificar os mecanismos, mas apenas de indicar suas tendências.

O método de investigação utilizado levou em conta a evolução do conhecimento em geoquímica de superfície nas últimas duas décadas, valorizando as observações e análises pontuais, considerando os microssistemas de alteração como sede dos fenômenos, e cuja justaposição forma e explica o todo do perfil e da paisagem.

Os trabalhos de campo foram orientados no sentido de observar e amostrar todas as fácies litológicas e de alteração, bem como as transições entre as diferentes fácies. Este trabalho foi favorecido graças à existência, na área, de cortes continuamente abertos e aprofundados pelos trabalhos de lavra de fosfato atualmente em curso.

Em laboratório, além da caracterização morfológica e mineralógica global do material, foram feitos fracionamentos granulométrico, densimétrico e magnético, estudos micromorfológicos, análises químicas qualitativas pontuais e algumas análises químicas totais e de elementos terras raras.

As técnicas analíticas utilizadas foram as seguintes:

- DRX: Difração de Raios-X (NUPEGEL e IG-USP);

- ATD: Análise Térmica Diferencial (IG-USP); USP);

- MO: Microscopia Óptica (NUPEGEL-

- ME: Microssonda Eletrônica (IG-USP);

- MEV: Microscopia Eletrônica de Varredura (NUPEGEL-USP, ORSTOM-França e CBMM);

- EDS: Sistema de Dispersão de Energia para microanálises químicas (NUPEGEL-USP, ORSTOM-França e CBMM);

- AA: Espectrofotometria de Absorção Atômica (IG-USP);

- AN: Ativação Neutrônica (IPEN).

\section{CARACTERIZAÇÃO DA ROCHA SÃ}

Segundo BORN (1971), o corpo carbonatítico de Juquiá é formado por dois volumes distin- 


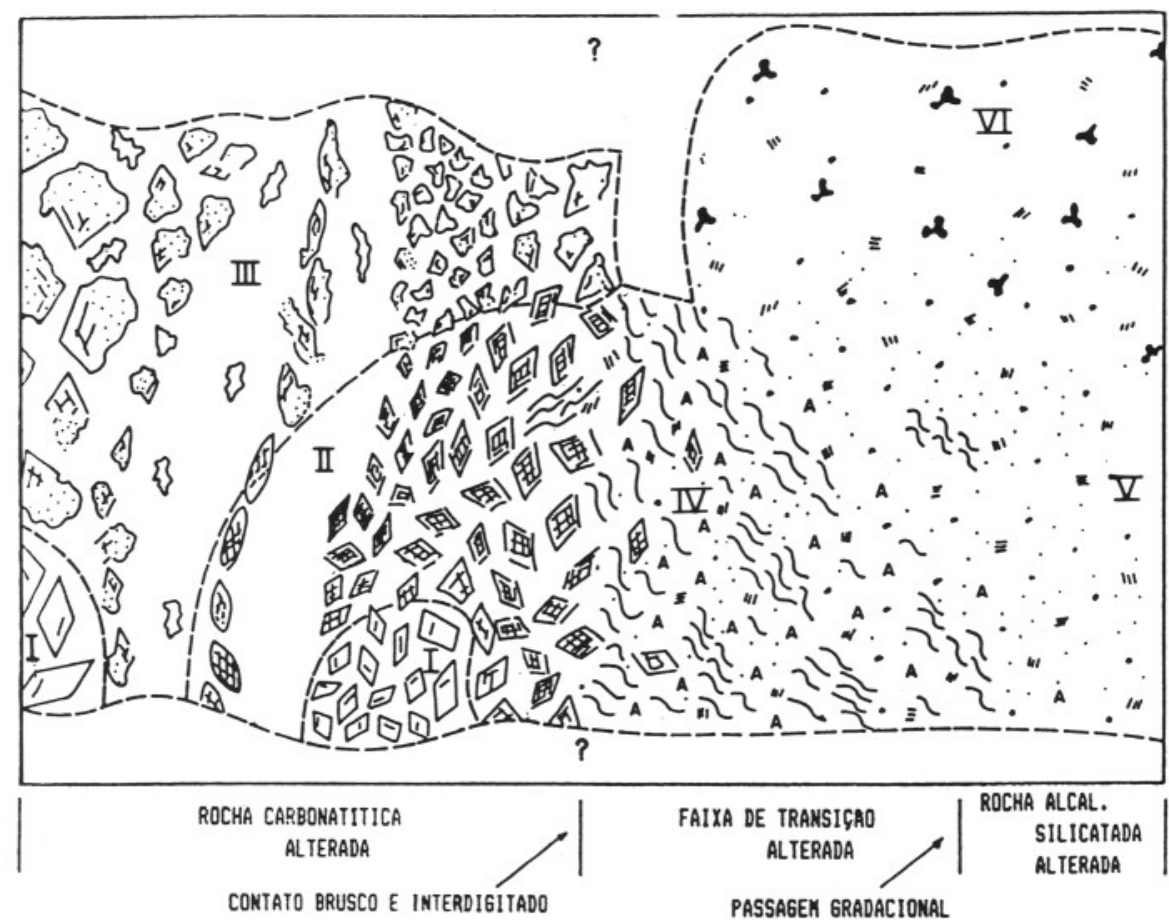

$I$ = Carbonatito ea initio de alt.;

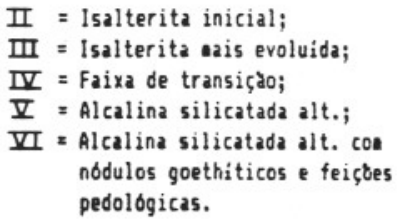

CARBONATITO:

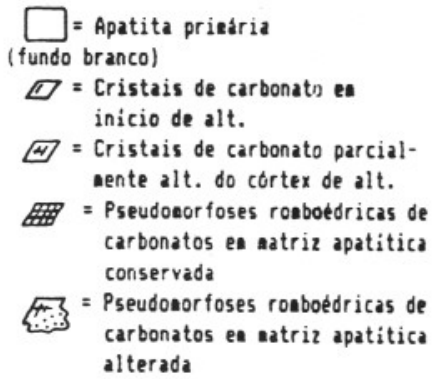

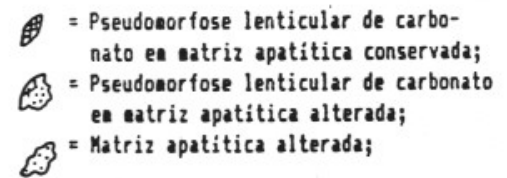

FAIXA DE TRANS. E ROCHA ALC. SIL. ALT.:

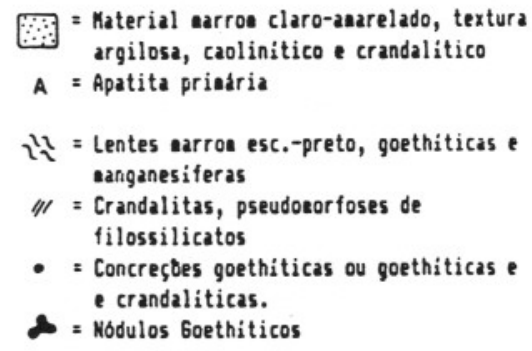

FIGURA 2 - Perfil de alteração esquemático sobre o carbonatito de Juquiá e a transição com a rocha alcalina silicática encaixante (sem escala).

tos: um interno, de composição anquerítica, e outro externo, beforsítico e rico em apatita.

Dados químicos de BECCALUVA et al. (1993) para o carbonatito de Juquiá confirmam a existência destes dois tipos. De maneira geral, aumentam os teores em $\mathrm{Sr}, \mathrm{Na}, \mathrm{Nb}, \mathrm{Y}, \mathrm{Ce}$ e $\mathrm{Ca}$ nas rochas mais apatíticas, correspondentes ao carbonatito externo, enquanto $\mathrm{Mn}, \mathrm{Ba}$ e V são mais característicos das rochas menos apatíticas.

$\mathrm{O}$ carbonatito estudado neste trabalho pertence ao tipo externo e foi descrito em ALCO-
VER NETO (1991), ALCOVER NETO \& TOLEDO-GROKE (1989) e WALTER (1991). Apresenta uma estrutura fluidal nítida, onde se alternam faixas ou lentes de comprimento métrico $(0,5$ a $5 \mathrm{~m})$ e espessura centimétrica (até cerca de $30 \mathrm{~cm}$ ) com variações texturais e mineralógicas. A granulação dos carbonatos é principalmente fina, milimétrica, podendo chegar a centimétrica; as apatitas são sempre milimétricas a submilimétricas. A variação mineralógica ocorre em termos da abundância relativa entre 
dolomita e apatita; existem desde faixas pobres em apatita até faixas muito ricas, seguindo a estrutura fluidal.

Além de dolomita e apatita, que ocupam, em geral, mais de $95 \%$ do volume da rocha, ocorrem como acessórios mais comuns flogopita, magnetita e barita, esta última em veios e bolsões centimétricos a decimétricos. Entre os raros, tem-se pirocloro, zircão e clorita.

Os carbonatos dolomíticos tendem ao idiomorfismo e podem apresentar-se zonados, feição esta reconhecida em análises ao MEV com EDS, que mostrou diferenciação química entre as partes internas e externas dos cristais; $\mathrm{Fe}, \mathrm{Mn}$ e $\mathrm{Sr}$ são freqüentemente detectados nas partes centrais, estando menos concentrados ou ausentes nas bordas. Em ambos os casos, o ferro é o mais importante dos três elementos.

A apatita pode representar até $50 \%$ do volume do carbonatito. Seus cristais de hábito prismático com eventual e leve tendência ao idiomorfismo são de formação posterior aos carbonatos. Podem atingir dimensões de até $0,4 \mathrm{~mm}$. Sua disposição evidencia a textura fluidal da rocha e foram separados em dois grupos distintos. Um deles é constituído por apatitas menores, aproximadamente ovais, variando de 0,05 a $0,1 \mathrm{~mm}$. O outro possui cristais maiores que podem atingir até $0,4 \mathrm{~mm}$ na sua maior dimensão. Em acordo com ALCOVER NETO (1991) e WALTER (1991), observou-se que as apatitas de menores dimensões são posteriores àquelas maiores.

Independentemente de suas dimensões, os cristais de apatita apresentam comumente inclusões fluidas e bordas de maior birrefringência, formadas por uma fase de carbonatação sobre a apatita preexistente que pode, em alguns casos, ter atingido todo o cristal, e não somente a borda.

WALTER (1991) observou que a presença de inclusões fluidas é uma particularidade das partes centrais dos cristais apatíticos. Quimicamente, as apatitas são enriquecidas em $\mathrm{Na}$ e $\mathrm{Sr}(0,2$ a $2 \%$ em óxidos) e, localizadamente, contêm pequenas quantidades de $\mathrm{Mg}, \mathrm{Fe}, \mathrm{Al}$ e $\mathrm{Mn}(0,05$ a $0,5 \%$ em óxidos) e, mais raramente, de $\mathrm{Ba}$ e $\mathrm{Pb}$ (0,1 a 0,3\% em óxidos). Considera, ainda, dois tipos distintos de composição química para as bordas de carbonatoapatita, onde $\mathrm{Sr}$ e $\mathrm{Na}$ podem chegar respectivamente a 4 e $2 \%$ em óxidos, segundo seus dados.

\section{O PERFIL DE ALTERAÇÃO}

Os trabalhos de mineração de fosfato no Morro do Serrote expuseram uma espessura de até cerca de $50 \mathrm{~m}$ de material intemperizado.

O carbonatito alterado propriamente dito, contínuo, é a litologia mais importante exposta nos perfis do Morro do Serrote. Macroscopicamente, nas partes inferiores e intermediárias do perfil, mantém a estrutura fluidal da rocha original.

Assim, o aspecto geral da alterita é o de uma rocha bandada, onde se alternam faixas claras (originalmente mais ricas em apatita) e faixas escuras (originalmente mais ricas em carbonatos, dissolvidos e com as cavidades correspondentes preenchidas parcialmente por produtos essencialmente ferruginosos), conforme a foto 1 .

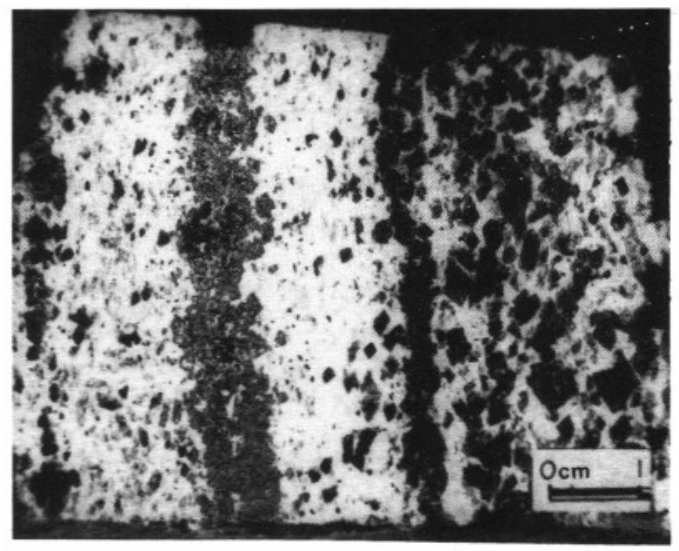

FOTO 1 - Estrutura fluidal do carbonatito em faixas diferenciadas pela proporção relativa entre os minerais principais (dolomita e apatita) e por sua granulometria, evidenciada na amostra alterada (face plana de amostra impregnada).

O material não é friável, já que a apatita primária sustenta o arcabouço da alterita; os minerais secundários ferruginosos e manganesíferos, quando separados do material, têm textura terrosa. Não há argilominerais, com exceção de locais restritos, onde houve influência da alteração das rochas alcalinas silicáticas encaixantes do carbonatito.

Na porção sudeste do Morro do Serrote, onde vem sendo lavrado o fosfato, aparecem, além dos produtos de alteração do carbonatito, materiais argilosos ligados à alteração das rochas alcalinas silicatadas onde se encaixa o carbonatito e ligados a um material gerado pela interação entre estas rochas na fase de intrusão.

Quatro fácies podem ser diferenciadas no perfil (figura 2):

- carbonatito em início de alteração,

- isalterita inicial,

- isalterita evoluída e

- zonas alteradas da transição entre o carbonatito e as rochas silicáticas alcalinas encaixantes.

Além destas fácies, integram ainda o perfil materiais aloteríticos e veios de barita. 


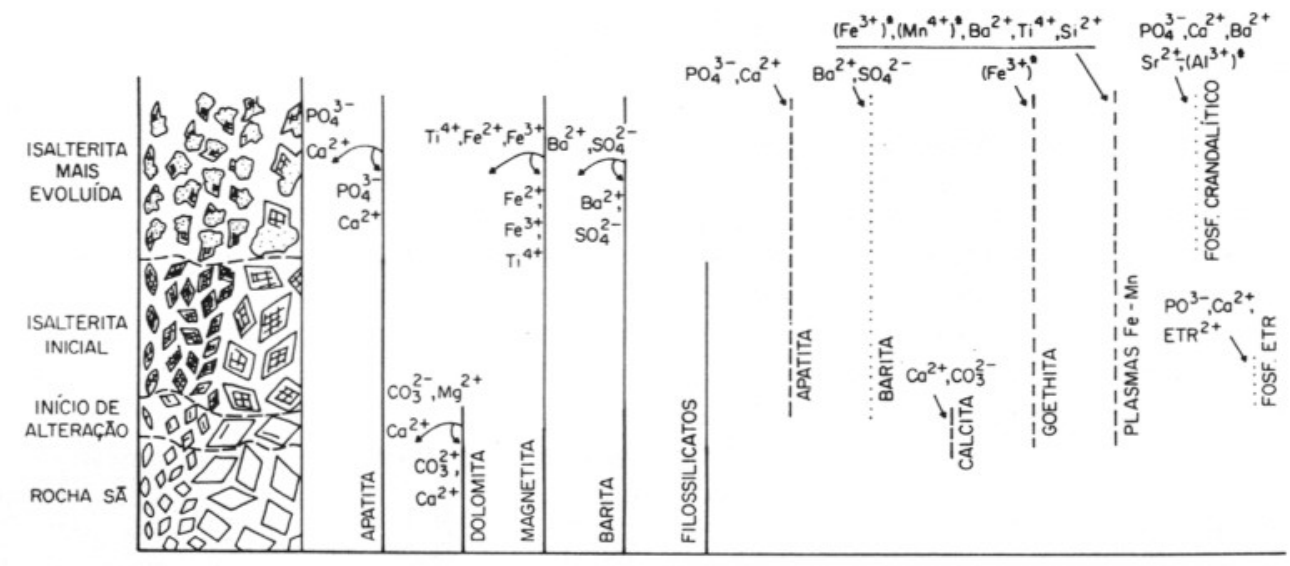

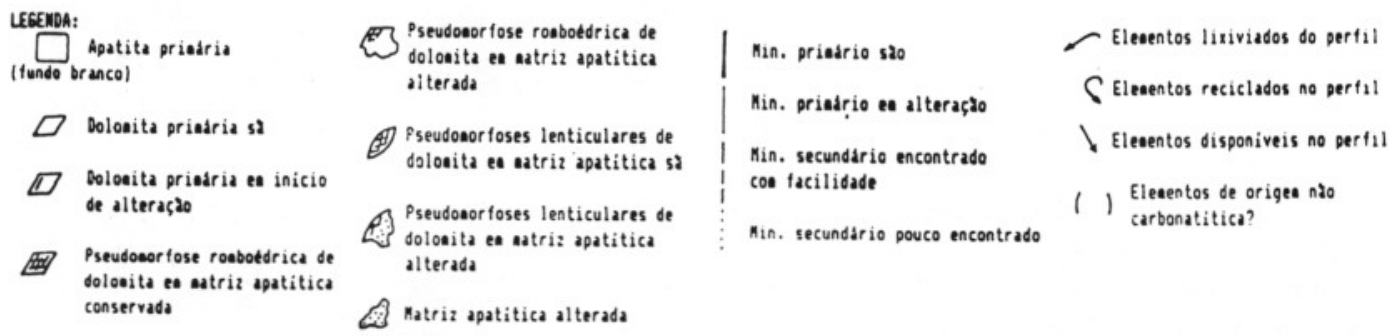

FIGURA 3 - Síntese da evolução morfológica, mineralógica e química da alterita desenvolvida a partir do carbonatito de Juquiá.

\subsection{Carbonatito em início de alteração}

O estágio inicial de alteração do carbonatito é registrado em materiais com pequena expressão em volume e caracteriza-se por:

- dissolução parcial dos cristais dolomíticos ao longo das descontinuidades inter e intraminerais, visível macro e microscopicamente;

- dissolução parcial dos planos de descontinuidade daqueles cristais por oxi-hidróxidos supérgenos de ferro e/ou manganês, iniciando a formação de pseudomorfoses por emparedamento (foto 2);

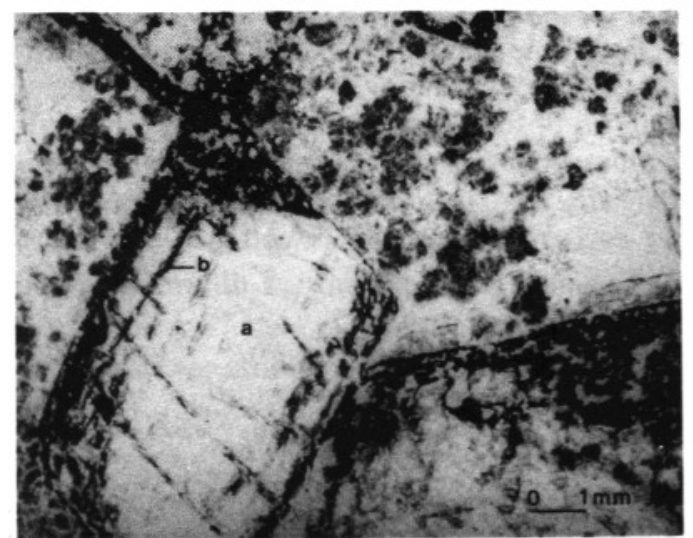

FOTO 2 - Cristais de dolomita em início de alteração (a) com produtos secundários ferruginosos e manganesíferos ocupando parcialmente os espaços de dissolução (b) (M. O, L. N). primária.

- conservação total dos cristais de apatita

Assiste-se, assim, nesta fase, a uma mobilização de íons $\mathrm{Ca}^{2+}, \mathrm{Mg}^{2+}$ e $\mathrm{CO}_{3}{ }^{2-}$ e a uma fixação de ferro e manganês, em parte alóctones, nos domínios dos cristais dolomíticos.

Associados a esses volumes carbonatíticos em início de alteração, observados tanto na vertente como na base do Morro do Serrote, foram encontrados depósitos brancos a incolores de calcita supérgena em camadas botrioidais com até $2 \mathrm{~cm}$ de espessura (foto 3 ). Observou-se que a cristalização desta calcita pode englobar fragmentos milimétricos do carbonatito, aparentemente substituindo-os progressivamente (foto 4 ).

\subsection{Isalterita inicial}

Esta fácies apresenta aspecto bandado pela alternância de faixas claras (originalmente mais ricas em apatita) e escuras (originalmente mais ricas em carbonatos, agora com ferruginização), sendo seu contato com o carbonatito em início de alteração marcado pela presença descontínua de material friável, formado por porções de rocha pobre em apatita. Neste material observa-se:

- ausência de carbonatos, já dissolvidos, deixando cavidades romboédricas na matriz apatítica primária;

- boa conservação da matriz apatítica primária, evidenciada pela perfeição dos limites das 


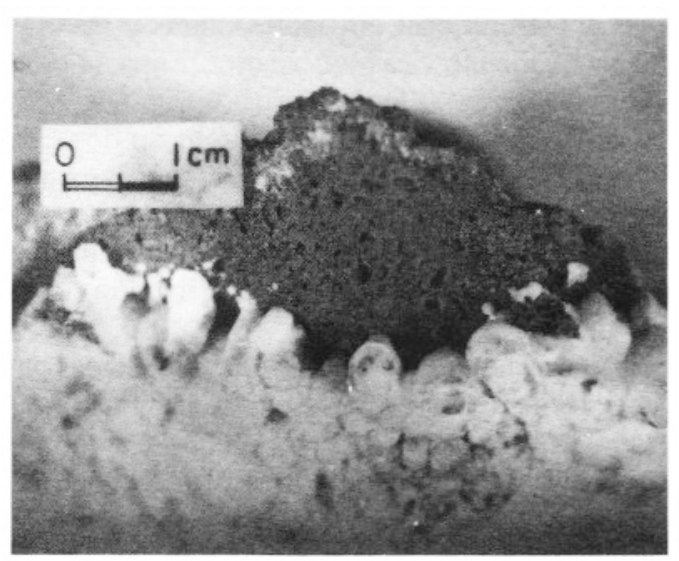

FOTO 3 - Calcita supérgena em fissura de carbonatito em início de alteração (amostra natural).

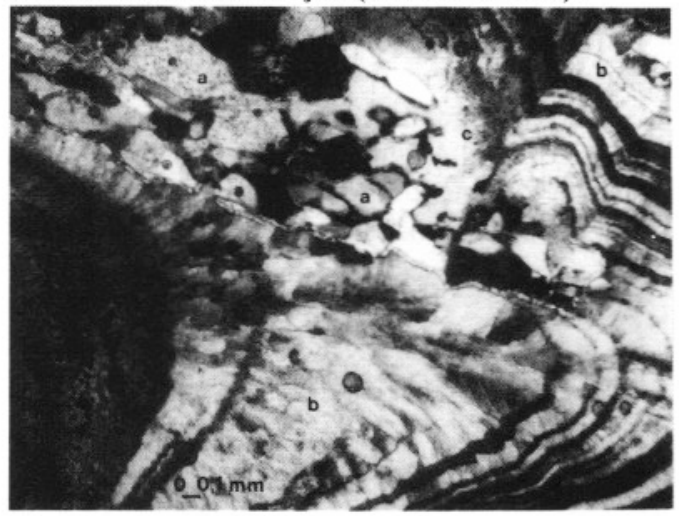

FOTO 4 - Calcita supérgena em formação de superfície botrioidal, englobando fragmentos de carbonatito (M. O, L. P); a: fragmento de carbonatito com cristais bem definidos de apatita; b: calcita supérgena fibrorradiada; c: zona de substituição progressiva da dolomita primária pela calcita secundária.

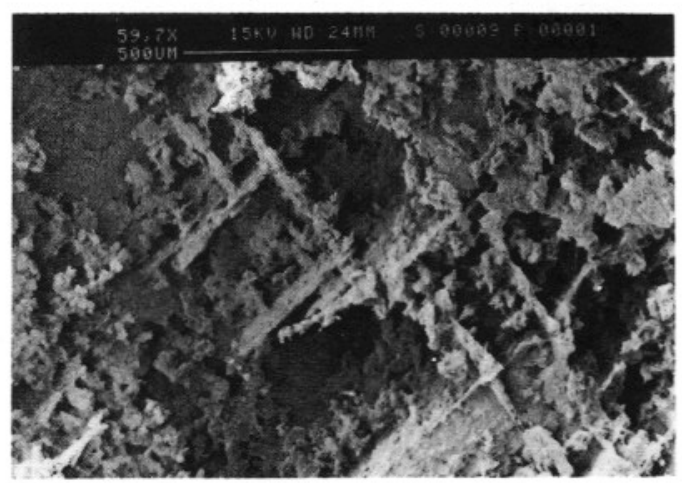

FOTO 5 - Fase ferruginosa supérgena formando paredes que sublinham descontinuidades de dolomita preexistente (M.E.V.).

cavidades romboédricas e eventualmente lenticulares da dissolução dos carbonatos (foto 1);

- ocupação parcial das cavidades pseudomórficas por produtos secundários oxihidróxidos de $\mathrm{Fe}$ e/ou Mn, amarelos, castanhos e pretos, e apatita em cristais hexagonais pris- máticos, incolores. Estes produtos ferruginosos estruturam-se de forma descontínua, segundo planos de clivagem do carbonato primário, conservando, assim, seu padrão geométrico em diferentes graus de organização (fotos 5, 6 e 7); - alteração parcial da magnetita, com formação de goethita ao redor;

- apatita supérgena, que ocorre nas seguintes formas:

a) em camadas de superfície botrioidal, ferruginizadas ou não, formadas por cristalização fibrosa sobre paredes de fraturas transminerais; estes depósitos podem ter até $2 \mathrm{~cm}$ de espessura (foto 8a e b),

b) em cristais idiomórficos (pirâmides hexagonais geminadas) milimétricos, vítreos de 1 a $4 \mathrm{~mm}$, sobre os depósitos botrioidais (foto 8c), e

c) em cristais prismáticos micrométricos vítreos de base hexagonal em conjunto com aspecto de "geodo", sobre superfícies de fissuras (foto 9);

- óxidos mistos primários de $\mathrm{Nb}$ e $\mathrm{Ta}$, com ou sem ETR e Ba, da família do pirocloro, bem conservados em meio à porosidade da apatita primária (foto 10 ),

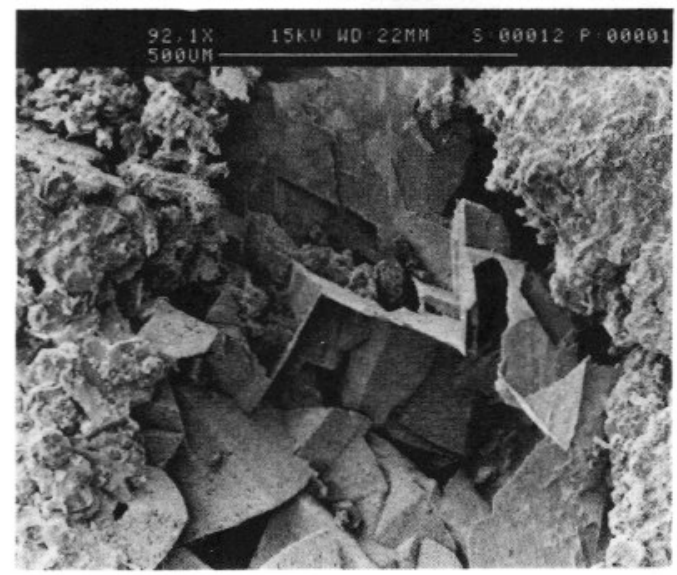

FOTO 6 - Conjunto de pseudomorfoses de dolomita por produtos ferruginosos (M.E.V.).

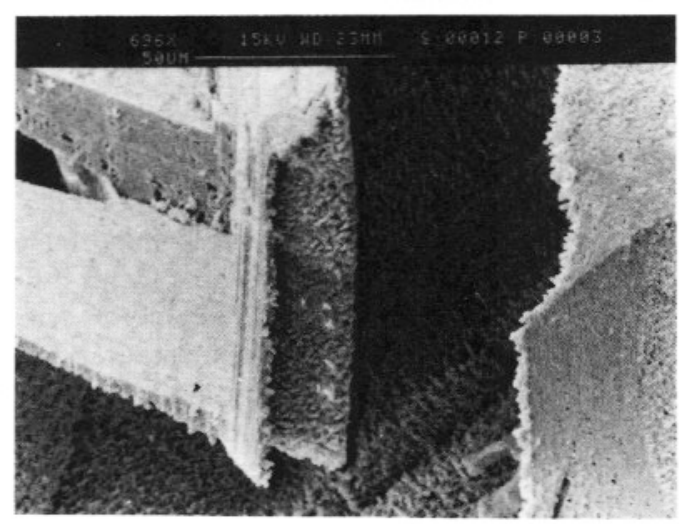

FOTO 7 - Detalhe da foto anterior, mostrando o hábito e organização dos oxi-hidróxidos de ferro (M.E.V.). 


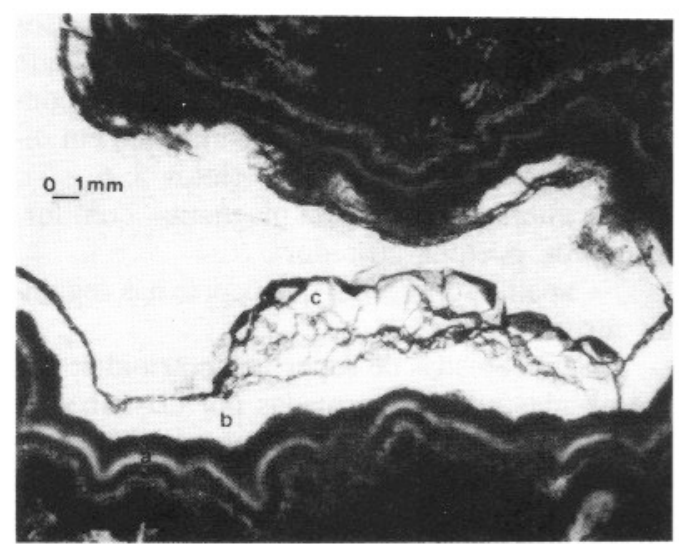

FOTO 8 - Depósito fissural de apatita supérgena a fibrosa com impurezas ferruginosas, b: fibrosa transparente e c: em pirâmides hexagonais transparentes (M. O., L. N).

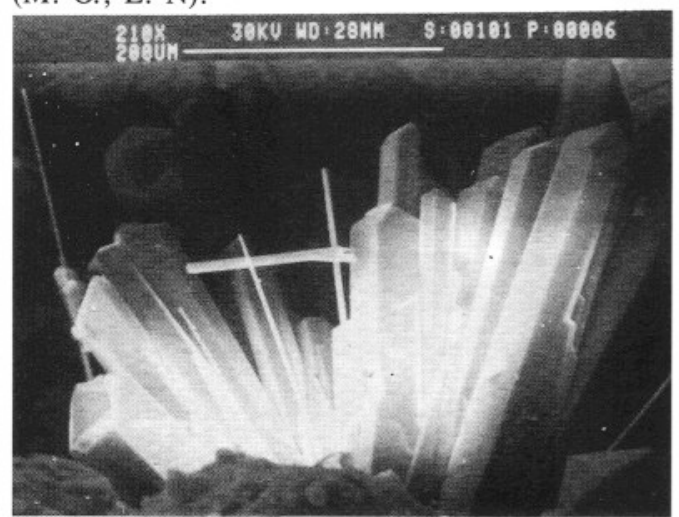

FOTO 9 - Apatita supérgena prismática hexagonal associada à fase ferruginosa (M.E.V.).

- fosfatos de ETR supérgenos, tipo monazita ou rabdofânio, com hábito globular, micrométrico $(+10 \mu \mathrm{m})$, ocorrendo na porosidade do material em alteração (foto 11), e

- fosfatos da família da crandalita, ricos em $\mathrm{Ba}$, com ETR, tipo gorceixita, de hábito romboédrico, micrométricos, na porosidade do material em alteração (foto 12 ).

\subsection{Isalterita evoluída}

A partir da isalterita inicial ou imediatamente após o carbonatito em início de alteração, o material passa a apresentar dissolução importante da matriz apatítica, caracterizando a fácies isalterita evoluída do carbonatito de Juquiá. Os cristais apatíticos apresentam basicamente três formas de desestabilização: a) desmonte em ripas (foto 13); b) dissolução localizada (foto 14); e c) dissolução generalizada, formando um material muito poroso, tipo couve-flor, de composição heterogênea, fosfática e ferruginosa (foto 15 ) e, localizadamente, associada a depósitos de apatita secundária em fissuras (foto 16).
A estruturação em lentes claras e escuras respectivamente ricas em apatita primária conservada e produtos ferruginosos supérgenos, ocupando vazios deixados pela dissolução dos carbonatos, continua evidente e, localizadamente, onde a apatita primária era pouco abundante e/ou onde a solubilização desta foi mais significativa, pode haver descaracterização da estrutura original da rocha.

O preenchimento das cavidades deixadas pelos carbonatos apresenta os mesmos constituintes já citados anteriormente, além de eventuais fragmentos da matriz apatítica primária em desestabilização.

Este material, como a fácies precedente, é cortado por freqüentes fraturas com deposição de apatita secundária, geralmente botrioidal. sidades.

Raramente, ocorre gorceixita em poro-

Micas (flogopita e clorita), alteradas em goethita e gorceixita, também podem ser encontradas, mas raramente, bem como minerais da família do pirocloro.

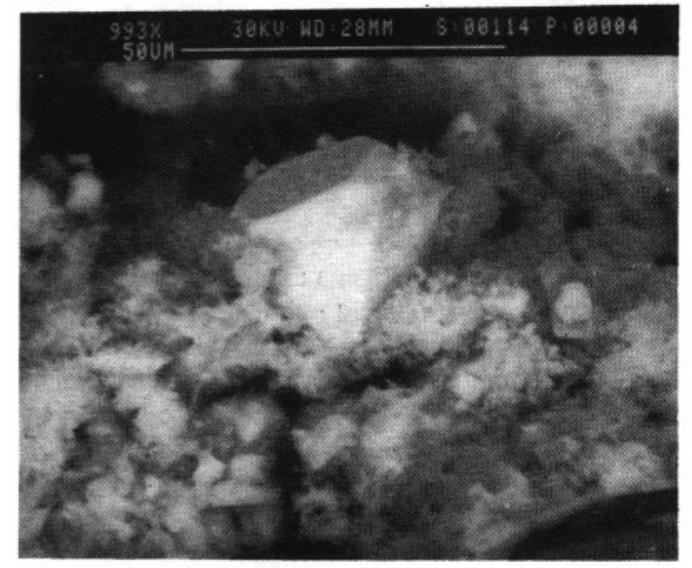

FOTO 10 - Pirocloro primário residual associado a produtos ferruginosos supérgenos em cavidade romboédrica pseudomórfica de dolomita (M.E.V.).

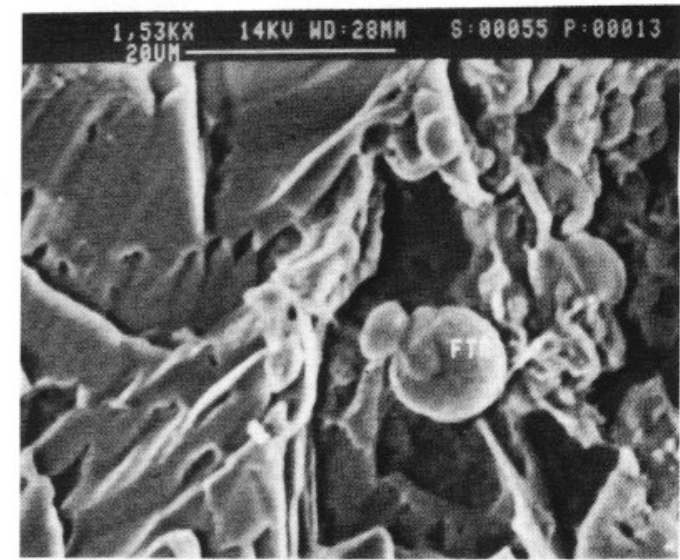

FOTO 11 - Fosfato supérgeno de elementos Terras Raras sobre carbonato primário parcialmente alterado (M.E.V.). 


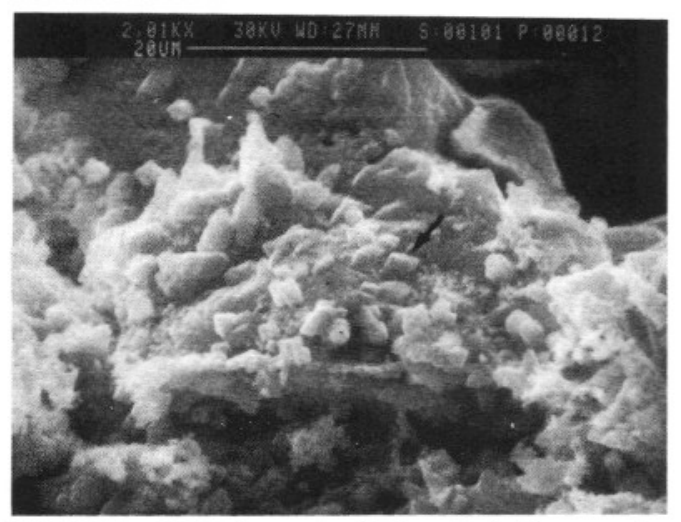

FOTO 12 - Cristais romboédricos de fosfato crandalítico (gorceixita) sobre matriz apatítica primária parcialmente dissolvida (M.E.V.).

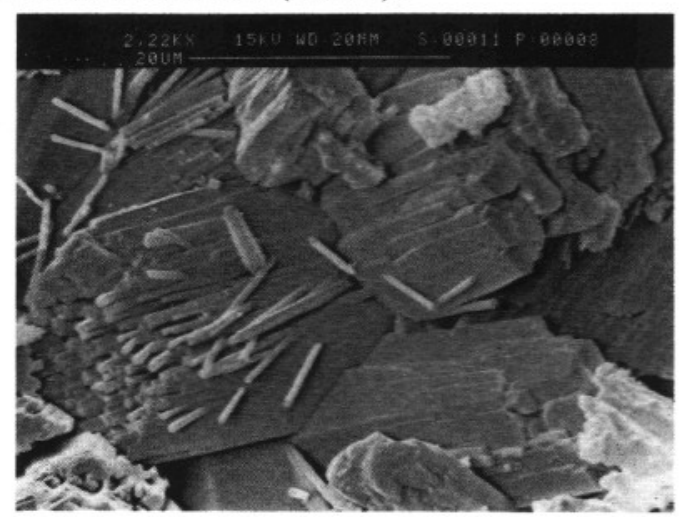

FOTO 13 - Alteração de apatita primária através de desmonte dos cristais em ripas (M.E.V.).

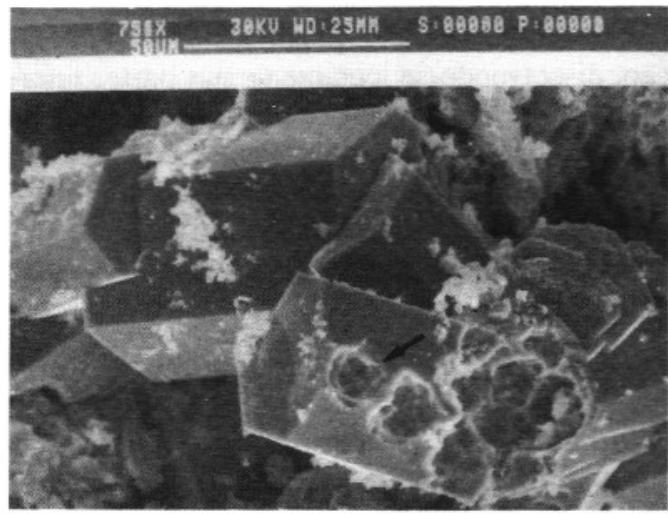

FOTO 14 - Alteração da apatita primária através da dissolução localizada dos cristais (M.E.V.)

\subsection{Alteração das zonas de transição (interação)} entre o carbonatito e as rochas silicáticas alcalinas encaixantes

A rocha alcalina silicática alterada observada no Morro do Serrote apresenta, de maneira geral, textura argilosa homogênea, coloração marrom-clara amarelada e é composta por caulinita, fosfato aluminoso (gorceixita), goethita e magnetita primária. Apresenta concreções milimétricas ( \pm
$3 \mathrm{~mm}$ ) de goethita e gorceixita. O caráter isalterítico nãoé evidente, mas foi considerada como isalterita devido à manutenção de vários planos de veios de barita hidrotermal a ela associados.

$\mathrm{O}$ seu contato lateral com a isalterita do carbonatito é feito através de uma zona de transição marcada pela ocorrência de um material com características mistas entre essas duas alteritas (figura 2). Pode também ocorrer em corpos irregulares decimétricos dentro da isalterita do carbonatito, correspondendo à alteração de xenólitos.

Nesta zona, o material é rico em apatita primária, macroscopicamente estruturada em trama tipo esponja, com cavidades de até $2 \mathrm{~cm}$, bastante fraturada, com características petrográficas semelhantes àquelas da rocha carbonatítica em diferentes estágios de alteração. O material argiloso marrom-claro amarelado, composto por caulinita, crandalita e goethita - preenche as cavidades da trama apatítica, deixando esta fácies com pequena porosidade. Outros materiais associados são:

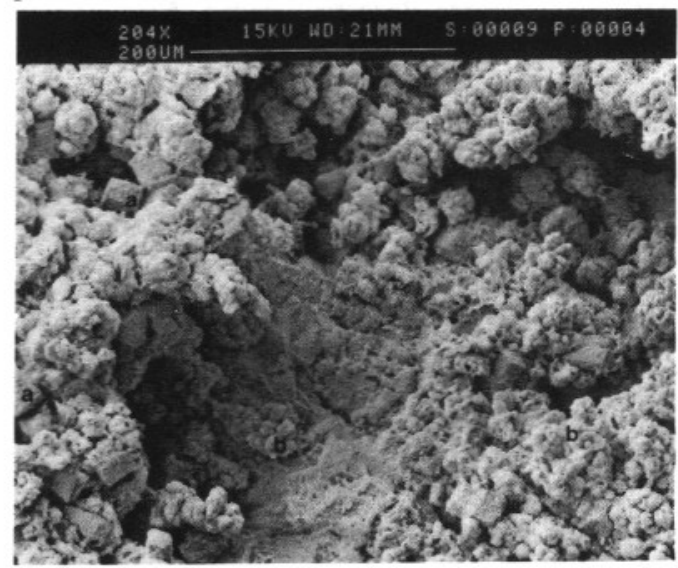

FOTO 15 - Apatita primária em vias de dissolução generalizada (a) associada a material poroso tipo "couve-flor", de composição fosfática ferruginosa (b) (M.E.V.)

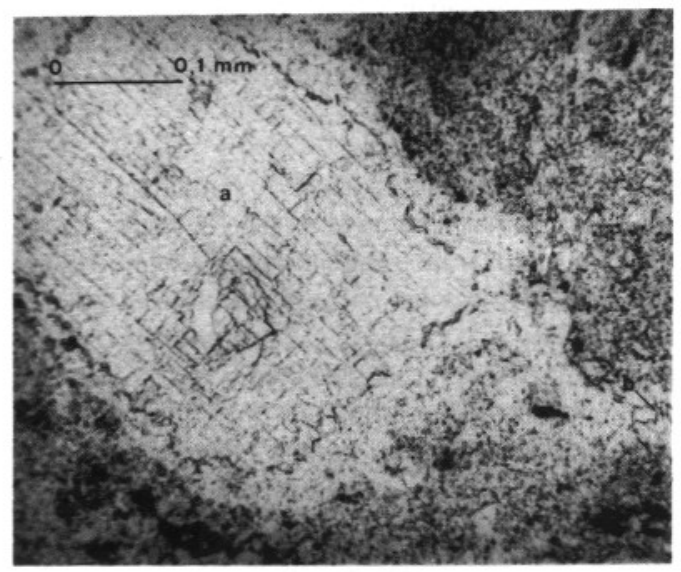

FOTO 16 - Apatita primária em vias de dissolução (a) associada a fissura transmineral com depósito tipo geodo de apatita secundária em cristais prismáticos (b) (M.O.,L.N.). 
a) faixas argilosas goethíticas e manganesíferas milimétricas, de coloração marrom-escura a preta, organizadas em aglomerações paralelas à orientação do contato $\mathrm{e}$

b) geodos alongados com até $20 \mathrm{~cm}$ de comprimento, constituídos por quartzo secundário incolor e vítreo.

\subsection{Materiais aloteríticos}

Associados às fácies isalteríticas mais evoluídas, são encontrados materiais em início de aloterização. Onde já não existem carbonatos e há intensa ferruginização, pode ser observada uma invasão das porções apatíticas da rocha pelo material ferruginoso. Este, além de deslocar mecanicamente fragmentos de apatita delimitados por descontinuidades ferruginizadas (foto 17), também parece, em alguns casos, promover uma epigenia da apatita. Assim, as zonas mais claras do material alterado tornam-se avermelhadas e progressivamente desestruturadas. Este parece ser o principal mecanismo de aloterização dos materiais provenientes da alteração dos carbonatitos.

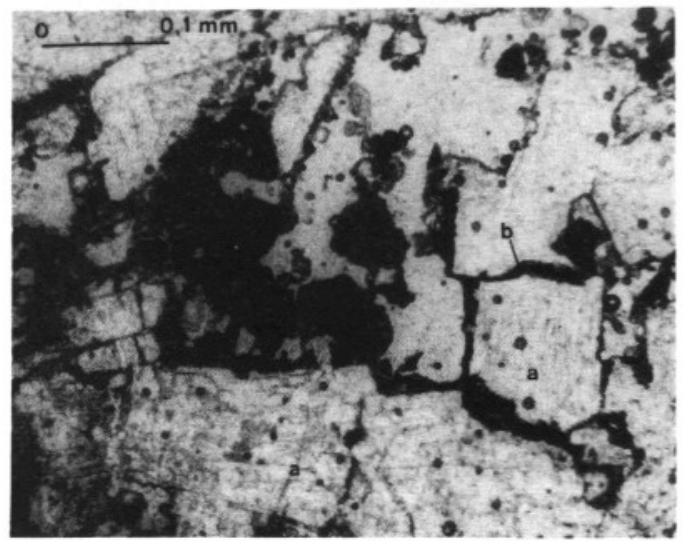

FOTO 17 - Invasão de descontinuidades da apatita (a) por produtos ferruginosos (b) com deslocamento relativo dos fragmentos do cristal (M.O.,L.N.).

Contudo, a maior parte dos materiais aloteríticos presentes na área tem outra natureza, tendo sido, por isto, relacionada a processos de alteração que envolveram não apenas as rochas carbonatíticas. São fácies argilosas pouco porosas, de cor marrom-clara amarelada, constituídas por caulinita, fosfatos aluminosos da família da crandalita e goethita, com apatita ocorrendo localizadamente.

Este material argiloso contém elementos nodulares, cuja abundância, dimensões e organização interna variam ao longo do perfil. Quando concrecionários, são constituídos por goethita e fosfatos de alumínio crandalíticos intercalados e suas dimensões variam de 1 a $20 \mathrm{~mm}$, aumentan- do para o topo do perfil. Quando simples nódulos, são constituídos por oxi-hidróxidos de ferro (goethita principalmente) e podem atingir dimensões até métricas nas partes superiores.

\subsection{Veios de barita}

Os veios de barita encaixados no carbonatito alterado do Morro do Serrote mostram vários estágios de evolução associados às diferentes fácies de alteração da rocha.

Quando sãos, seus cristais são vítreos, incolores a esverdeados e com hábito prismático tabular.

O início da alteração dá-se por dissolução interna, nos planos de clivagem, e externa, na superfície dos cristais, tornando-os opacos e com ferruginização eventual nestas descontinuidades. A evolução da alteração leva à sua dissolução total, o que é comprovado pela ocorrência de pseudomorfoses de seus cristais, tanto na matriz apatítica primária como na apatita supérgena depositada sobre os antigos cristais de barita, já dissolvidos, formando moldes.

\section{O FÓSFORO E OS FOSFATOS NO PERFIL DE ALTERAÇÃO}

\section{Apatita primária}

A apatita primária, essencialmente fluorapatita, que pode apresentar-se com uma coroa de carbonatoapatita de origem primária (tardimagmática), caracteriza-se pela resistência à alteração, dissolvendo-se lentamente nas partes intermediárias do perfil, mas mantendo-se em grande parte intacta, a ponto de sustentar o arcabouço isalterítico. Sua dissolução lenta e tardia fornece material para a precipitação de fosfatos secundários, o que é evidenciado pelas várias gerações de apatita supérgena observadas nos depósitos fissurais e porosidades em geral.

\section{Apatita supérgena}

As apatitas supérgenas ocorrem ao longo de toda a isalterita:

- nas cavidades romboédricas ou alongadas irregulares, em cristais submilimétricos, ripiformes e vítreos, associados a produtos ferruginosos (goethita e outros mal cristalizados),

- nas fissuras transminerais, como depósitos sucessivos de cristais perpendiculares às paredes, com aspecto fibroso em corte e mamelonar em superfície, geralmente brancos translúcidos, com brilho perláceo e

- sobre os depósitos acima ou diretamente sobre a matriz apatítica primária, como cristais vítreos, bem formados, em prismas ou pirâmides achatadas, milimétricos, isolados ou em as- 
sembléias tipo geodos ou aglomerados até centimétricos.

\section{Fosfatos de alumínio}

Os fosfatos da família da crandalita, citados anteriormente, têm composição próxima ao pólo gorceixita (com bário), mas com traços de estrôncio e de terras raras, dentro, portanto, da solução sólida gorceixita-goyazita-florencita, segundo indicaram as análises pontuais qualitativas por EDS em MEV.

Esses fosfatos, detectados também por DRX e ATD, ocorrem em maior escala nos materiais aloteríticos argilosos acima da isalterita do carbonatito, junto com caulinita e goethita, imersos na massa argiloferruginosa e não diferenciáveis ao MO. Ocorrem também na isalterita, onde as análises ao MEV os evidenciaram, associados a locais particulares, ricos em micas ou nos domínios de xenólitos das rochas silicáticas dentro do carbonatito.

\section{DISCUSSÃO}

Os perfis de alteração observados, desenvolvidos a partir das rochas carbonatíticas de Juquiá, mostraram manutenção do volume original da rocha, tratando-se portanto de uma isalterita. A grande responsável pela manutenção desta estrutura, aproximadamente $140 \mathrm{~m}$ mais alta que a altitude regional média, é a apatita residual que ocupa volume importante na rocha original e é bastante resistente à alteração supérgena.

A composição beforsítica do carbonatito original, com altos teores em ferro e manganês, propicia o acúmulo de oxi-hidróxidos secundários destes elementos na alterita, onde a contribuição alóctone também deve ser considerada. Localizadamente, ficou clara a participação destes elementos, principalmente o ferro, na formação de pseudomorfoses de carbonatos, sem que tenham tido um papel fundamental na manutenção das estruturas litológicas na parte isalterítica do perfil.

O processo de lateritização do corpo carbonatítico caracteriza-se pela baixa concentração de espécies de silício e alumínio nas soluções lixiviantes, haja vista a baixa concentração desses elementos nos minerais neoformados encontrados na laterita, relacionada à sua pobreza na rocha inicial. Este processo de lateritização pode ser dividido em dois estágios evolutivos distintos: a) um estágio inicial, onde predomina a dissolução dos carbonatos e as águas percolantes, presumivelmente ricas em $\mathrm{HCO}_{3}{ }^{-}$, apresentam $\mathrm{pHs}$ alcalinos inadequados à dissolução da apatita, e b) outro estágio posterior, onde, após total alteração dos carbonatos, as soluções perdem o caráter alcalino e a apatita mostra dissolução importante.
Os estágios lateríticos mais evoluídos mostram a epigenia das apatitas primárias por plasmas ferruginosos e manganesíferos, cuja instalação também causa deslocamentos mecânicos do material residual. Começa aí o processo de aloterização que ainda é pouco conhecido.

Os minerais acessórios apresentam pouca influência no processo de meteorização do carbonatito de Juquiá. Os filossilicatos são rapidamente alterados, juntamente com os carbonatos da rocha, e não mostram transformações em argilominerais, sendo suas pseudomorfoses ferruginosas formadas provavelmente em grande parte por ferro residual e eventualmente alóctone. Os cristais de magnetita podem ser encontrados em vias de desestabilização nos estágios iniciais de alteração da rocha; porém, sua cinética lenta de dissolução, sob as condições reinantes em Juquiá, preserva-os por longo tempo, e são encontrados apenas parcialmente alterados junto às fácies supérgenas mais evoluídas do carbonatito. A barita também se altera por dissolução.

Dentre os minerais neoformados, os produtos ferruginosos são os mais abundantes, encontrados em todas as fases de evolução da alterita estudada. Foram encontrados nos estágios iniciais da alteração do carbonatito, ocupando parcialmente os espaços deixados pela dissolução dos carbonatos, podendo formar pseudomorfoses em diferentes níveis de organização. Recobrem materiais primários e secundários, principalmente aqueles apatíticos, como filmes ferruginosos. Estão presentes nas fases mais evoluídas de alteração sob a forma de plasmas com ou sem apatita residual e marcando depósitos botrioidais fibrorradiados de apatita secundária. Dentre estes produtos, foi observada a existência de dois grupos geoquímicos bem diferenciados; um deles, mais abundante, contém manganês e o outro é caracterizado pela presença de titânio, indicando tratarse de produtos de alteração da magnetita. Esta diferenciação parece mostrar produtos ferruginosos de origens diferentes ainda não homogeneizados.

A presença de fosfatos supérgenos não apatíticos foi pouco observada nos materiais provenientes do carbonatito. Fosfato de ETR, de formato globular, foi encontrado em apenas uma amostra. Fosfato de alumínio da família das crandalitas foi identifcado somente em amostras próximas à rocha alcalina silicática encaixante alterada, mostrando hábito romboédrico e composição próxima à gorceixita (rica em bário), com algum estrôncio subordinado. A inexistência destes fosfatos crandalíticos na alteração do carbonatito evidencia a carência em alumínio para a sua formação durante a evolução da alterita do carbonatito, uma vez que na alterita sobre as rochas alcalinas silicáticas do Complexo de Ju- 
quiá, onde alumínio e fósforo são abundantes, os fosfatos crandalítico são fase importante e facilmente identificada. Além deste, ocorre, raramente, barita com características morfológicas indicando caráter supérgeno.

De modo geral, ocorrem as seguintes evoluções mineralógicas na isalterita do carbonatito de Juquiá:

a) dolomita I

- . > dissolução

... > calcita II

. . . > oxi-hidróxidos II de Fe/Mn*

b) apatita I

- - > apatita II

. . . > fosf. crandalítico II*

. . . > fosf. de ETR II*

- . - > dissolução

c) magnetita I

- . - > goethita II

. . - > oxi-hidróxidos II de Fe/Ti

- . - > dissolução

d) barita I

. . - > barita II

... > dissolução

e) filossilicatos I

... > goethita II*

- . - > oxi-hidróxidos II de Fe/Mn*

. . . > fosf. crandalítico II*

... > dissolução

(*: mineral secundário formado com contribuição alóctone, I: primário, II: secundário)

No caso específico da filiação mineralógica da apatita primária, há concordância com aquela proposta por VIELLARD et al. (1979), LUCAS et al. (1980), FLICOTEAUX \& LUCAS (1984) e SCHWAB et al. (1989), que se apóiam em dados termodinâmicos, sendo que a seqüência evolutiva aqui observada foi mais restrita (ap I $\rightarrow$ ap II $\rightarrow$ fosf $\mathrm{Al}$ ). Os fostatos de ETR, não comentados pelos autores acima, foram considerados aqui como evolução direta da apatita primária; porém, a possibilidade de produtos intermediários, fosfatados ou não, deve ser considerada, embora não tenham sido detectados.

O quimismo envolvido na fase inical do processo de lateritização do carbonatito de Juquiá apresentou grande disponibilidade de $\mathrm{CO}_{3}{ }^{2-}$, $\mathrm{Ca}^{2+}, \mathrm{Mg}^{2+}, \mathrm{Fe}^{2+/ 3+}, \mathrm{Mn}^{4+}, \mathrm{Ba}^{2+}$ e $\mathrm{Sr}^{2+}$, tendo em vista a composição apresentada pelos car- bonatos primários analisados. Os íons $\mathrm{CO}_{3}{ }^{2-}$, $\mathrm{Ca}^{2+}$ e $\mathrm{Mg}^{2+}$ sofrem lixiviação quase total, sendo que alguma calcita supérgena, em quantidade relativamente pouco importante, é fixada na base do perfil. Ferro e manganês são fixados nos estágios iniciais de dissolução dos carbonatos, provavelmente como $\mathrm{Fe}^{3+}$ e $\mathrm{Mn}^{4+}$ em oxi-hidróxidos, e podem conter localizadamente algum $\mathrm{Ba}^{2+}$ e $\mathrm{Sr}^{2+}$. Esses dois últimos íons são também incorporados nas estruturas crandalíticas secundárias.

No segundo estágio da alteração há grande disponibilidade geoquímica de $\mathrm{PO}_{4}{ }^{3-}$ e $\mathrm{Ca}^{2+}$ nas águas percolantes. Parte destes elementos é, provavelmente, lixiviada, mas a recristalização de apatita supérgena é abundante e mostra uma purificação e descarbonatação em relação à apatita original.

Os plasmas supérgenos desenvolvidos neste estágio são predominantemente ferruginosos e manganesíferos e, apesar de não terem sido encontrados, deve-se considerar a possibilidade de formação de fostatos mistos de $\mathrm{Ca}$ e $\mathrm{Fe}$ nestes materiais, já que eles mostram algum teor em fósforo.

Em comparação com outros maciços similares brasileiros, Juquiá constitui um exemplo extremo de enriquecimento em fósforo residual apatítico, devido ao caráter contínuo do carbonatito que lá ocorre. Esta situação diverge daqueles outros locais, onde as rochas carbonatíticas estão sob a forma de veios e diques associados às rochas alcalinas silicáticas, havendo participação significativa, nos perfis de alteração, de outras fases mineralógicas além dos carbonatos e fosfatos, que representam, no caso aqui estudado, a quase totalidade da composição mineralógica.

A figura 3 esquematiza as principais evoluções morfológicas, mineralógicas e químicas envolvidas na formação da alterita do carbonatito de Juquiá, sintetizadas neste trabalho.

\section{AGRADECIMENTOS}

Os autores agradecem à FAPESP e CAPES pelo apoio financeiro durante a realização deste trabalho, bem como à SOCAL Mineração pelo apoio aos trabalhos de campo, à ORSTOM pelo acesso aos seus laboratórios e aos Drs. René Flicoteaux e Anne-Veronique Walter, que também trabalharam na área, pela colaboração científica.

\section{REFERÊNCIAS BIBLIOGRÁFICAS}

ALCOVER NETO, A. \& TOLEDO-GROKE, M.C. 1989. Caracterização preliminar da evolução supérgena das rochas carbonatí- ticas do complexo alcalino-carbonatítico de Juquiá-SP, com enriquecimento em fosfatos. In: Congr. Bras. Geoquímica, 2, Rio 
de Janeiro, 1989, Anais, Rio de Janeiro, Sociedade Brasileira de Geoquímica, CPRM, DNPM, p. 479-486.

ALCOVER NETO, A. 1991. Evolução supérgena das rochas carbonatíticas ricas em apatita do complexo alcalino de Juquiá (SP). Diss. Mestr. IG-USP, São Paulo, 131 p. (inédito).

BECCALUVA, L. et al. 1993. Journal of Petro$\log y$ (no prelo).

BORN, H. 1971. O complexo alcalino de Juquiá. Tese Dout. IG-USP, São Paulo, 200 p. (inédito).

FLICOTEAUX, R. \& LUCAS, J. 1984. Weathering of phosphate minerals. In: Phosphate Minerals Springer Verlag, Nriagu \& Moore, editors. p. 292-317.

LUCAS, J.; FLICOTEAUX, R.; NATHANY, Y; PRÉVÔT, L. \& SHALAR, Y. 1980. Different aspects of phosphorite weathering, SEPM Special Public. 29: 41-51.

MACCIOTTA, G.; BARBIERI, M.; BECCALUVA, L.; BORN, H.; BROTZU, P.; CONTE, A.; GARBARINO, C.; GOMES, C.B.; MORBIDELLI, L.; RUBERTI, E.; SCIENA, F. \& TRAVERSA, G. 1988. Petrological and geochemical studies of alkaline rocks from continental Brazil. The Juquiá intrusive alkaline-carbonatite complex, state of São Paulo. In: Intern. Conf. "Geochem. evol. of the contin. crust", Poços de Caldas, 1988. Abstracts, Poços de Caldas, p. 92-97.

RODRIGUES, C.S. \& LIMA, P.R.A.S. 1984. Complexos carbonatíticos do Brasil. In:
Complexos carbonatíticos do Brasil: geologia. CBMM, São Paulo, p. 1-17.

SCHWAB, R.G.; HEROLD, H.; COSTA, M.L. \& OLIVEIRA, N.P. 1989. The formation of aluminous phosphates through lateritic weathering of rocks. In: Balasubramanian, K.S. (ed.), Weathering its products and deposits. Athens, Theophrastus, v. 2, p. 369-386.

SONOKI, I.K. \& GARDA, G.M. 1988. Idades $\mathrm{K}$-Ar de rochas alcalinas do Brasil meridional e Paraguai oriental. Compilação e adaptação às novas constantes de decaimento. Bol. IG-USP Série Científica, 19: 63-85.

THE BRITISH SULFUR CORPORATION LIMITED. 1980. World survey of phosphate deposits. London, $237 \mathrm{p}$.

ULBRICH, H.H.G.J. \& GOMES, C.B. 1981. Alkaline rocks from Brazil. Earth Science Reviews, 17: 135-154.

VIEILLARD, Ph.; TARDY, Y. \& NAHON, D. 1979. Stability fields of clays and aluminium phosphates paragenesis in lateritic weathering of argillaceous phosphatic sediments. American Mineralogist, 64: 626-634.

WALTER, A.V. 1991. Caractérization géochimique et minéralogique de l'altération de la carbonatite du Complexe Alcalin de Juquiá (Brésil) - Compartement des Terres Rares dans les minéraux phosphatés. Thèse, Univ. d'Aix Marseille, $247 \mathrm{p}$.

ZANIN, Y.V.N. 1968. Zones of lateritic weathering of secondary phosphorites of AltaySayan region. Internat. Geology Review. 10 (10):1.119-1.127.

- Arnaldo Alcover Neto - Instituto de Geociências, Universidade de São Paulo - Programa de pós-graduação em Geoquímica e Geotectônica (PPGGG) - Caixa Postal 20.899 - 01498-970 - São Paulo, SP - Brasil.

- Maria Cristina Motta de Toledo - Instituto de Geociências, Universidade de São Paulo - Núcleo de Pesquisas em Geoquímica e Geofísica da Litosfera (Nupegel) - Caixa Postal 20.899 - 01498-970 - São Paulo, SP - Brasil. 